\title{
Review of traffic control techniques for emergency vehicles
}

\author{
Wan Mohd Hafiz bin Wan Hussin, Marshima Mohd Rosli, Rosmawati Nordin \\ Faculty of Computer and Mathematical Sciences, Universiti Teknologi MARA, Shah Alam, Selangor, Malaysia
}

\begin{tabular}{l} 
Article Info \\
\hline Article history: \\
Received Sep 15, 2018 \\
Revised Nov 20, 2018 \\
Accepted Dec 25, 2018 \\
\hline
\end{tabular}

\section{Keywords:}

Emergency vehicles Image processing RFID

Traffic light

Wireless sensor network

\begin{abstract}
Traffic control system play an important role to manage traffic congestion on the road especially during peak hours and peak seasons. One of the main challenges is to control the traffic when there are emergency cases at traffic light intersection especially peak hours. This could affect the route for emergency vehicles such as ambulance, fire brigade and police car to reach their destination. Due to the increase of traffic congestion during peak hours and peak seasons in Malaysia, there is a need for further evaluation of traffic control techniques. This paper reviewed and consolidated information on the different types of the existing traffic control system for road traffic management such as Radio Frequency Identification (RFID), wireless sensor network and image processing. This paper analysed and compared on the design, benefits and limitations of each technique. Through the reviews, this paper recommends the best traffic control technique for emergency vehicle that offers low price, low maintenance and can be used in various areas of applications.
\end{abstract}

Copyright $\odot 2019$ Institute of Advanced Engineering and Science. All rights reserved.

\section{Corresponding Author:}

Marshima Mohd Rosli,

Department of Computer Science,

Universiti Teknologi MARA,

Shah Alam Selangor Malaysia

Email: marshima@tmsk.uitm.edu.my

\section{INTRODUCTION}

The majority of the urban communities in Malaysia have seen significant population and financial development over the past two decades. As a result of this development, there was an increase in the number of registered vehicles on the road. Therefore, in 2017, there were more than 28 million registered vehicles in Malaysia [1]. This indicates the critical difficulties and also issues to a nation with just more than 8 million household especially for the transportation problems in the urban areas.

One of the general transportation problems for the urban areas in Malaysia is when there are emergency cases at the traffic light intersection which are always busy with many vehicles. This will cause the emergency vehicles difficult to reach the destination on time due to the traffic congestion particularly during peak hours. In some cases, the emergency vehicles such as fire brigade and ambulance face difficulties when they have to wait for other vehicles to give way at intersections with traffic lights [2]. This can cause delay emergency vehicles such as fire brigade to rescue the people, police car to catch the thief, ambulance to reach hospital on time. Moreover, the collisions with other vehicles from other ways of direction might also occur at the intersections with traffic light. This also will cause a delay of time and may affect the emergency case such as loss of life and property [2]. Improving the existing traffic control system is therefore significantly important to solve the difficulties faced by the emergency vehicles.

In recent years, there has been an increasing interest in the smart traffic control system by using RFID, wireless sensor network and image processing that studied the alternative ways to enhance the existing traffic control system [3]. These technologies able to support the traffic control system to make traffic routing decision when emergency cases occur. For example, a smart traffic control system can replace the policeman or traffic marshals that control the routing decision during congestion at the intersection with traffic light [3]. 
In this study, we present a review on the techniques of the traffic control system for road traffic management. The objective of this review is to update the status of the degree to which techniques on the traffic control system are addressed in the technology research. The review addresses two research objectives: (1) To compare the advantages and disadvantages of each technique that has been used. (2) To suggest an appropriate technique to improve the current system.

The remaining of this paper is organized as follows: Section 2 describes the background and motivation and Section 3 describes the methodology to perform the review. Section 4 presents the results of the review and section 5 describes the propose method to improve the current traffic control system. Section 6 discuss on the importance of the review results. Finally, this paper concludes and suggests future work in section 7 .

\section{BACKGROUND AND MOTIVATION}

There are some other factors that might cause traffic congestion on the road and the researchers need to do some research on how to reduce congestion on the road such as:

\subsection{Weakness in the existing traffic light control system}

Basically, the main function of traffic light control is to control the flow of traffic. The normal form of traffic light is comprises of simple three colors for traffic signal which are red means stop, yellow means ready to stop and green means move. This general traffic light control system cannot give prioritize and recognize the emergency vehicle and normal car. As an example, the delay of the ambulance to reach at the hospital because of the traffic congestion may cause danger to patient's life.

On another side, the normal form of the traffic management is requires police traffic on the road to control the traffic congestion. The police traffic will control the flow of traffic during traffic congestion occurred by gives the signal to the road's user whether to drive or stop. The police traffic can recognize and give priority for the emergency vehicles by giving way to the emergency vehicles.

\subsection{Weakness in the existing emergency vehicles system.}

The existing emergency vehicle system in Malaysia is by using the radio system and then connected with a call center. The emergency vehicles just give a flashing light and loud siren to warn the road's user that the emergency vehicles need the right of way. Sometimes, flashing light and loud siren do not give an affect to road users due to an issue that is some road users are hearing the radio with high volume, no space to give way and other interferences. Therefore, this kind of issue may contribute factors for the emergency vehicles to reach the destination smoothly.

\section{METHODOLOGY}

This paper uses a narrative literature review approach to compare and summarize on the existing techniques of traffic control system in the literature. The narrative literature review approach aims to discuss the state of a specific topic or theme from a theoretical and contextual point of view. This paper analysed the selected studies based on the following criteria:

a) Techniques used to control traffic routing decisions.

b) Traffic data collection methods to manage the routing decisions.

c) Number and types of variables use to support the routing and signal decisions.

\section{TECHNIQUES FOR TRAFFIC CONTROL SYSTEM}

In recent years, there has been an increasing amount of literature on solving the problem of the traffic congestion. This paper reviewed relevant publications that discussed the common techniques used for traffic congestion which are RFID, wireless network sensor and image processing. The detail of each technique is explained in the following subsection.

\subsection{RFID}

Generally, RFID is a suitable approach that can be used to control the traffic congestion. RFID are divided into three types which are low frequency (LF), high frequency (HF) and ultra-high frequency (UHF) bands [4]. The various types of bands can produce different results in terms of accuracy and precision to detect.

Hashim et al. [5] propose a RFID technique to control the traffic congestion vehicle (VTCE). The proposed technique used the RFID Reader in the vehicle to read the vehicle tag and transfer the required 
information to the database in the Central Computer System. The Central Computer System will determine the traffic congestion status of the road network by following certain procedures based on the data obtained from the Central Computer System (CCS). The results of the study indicate that the VTCE system had been successful by introducing RFID readers at each of the intersection points and adding RFID labels to all vehicles.

However, unlike Suresh et al. [6] which explains that by using RFID it is possible to avoid problems arising from normal light control systems associated with beam interference techniques and image processing. Suresh et al proposed a technique that use a RF reader on the road intersection to consider the priority for the emergency vehicles and the density of the traffic on the roads. The results show that it can reduce time efficiently and give dynamic time in real time to avoid traffic congestion.

Raju et al. [7] made further support by integrating RFID and Global System for Mobile communication (GSM) to control the traffic congestion. However, it only focuses on ambulance to prove this methods. As an example, once an ambulance reach the traffic light junction, it corresponding lane traffic light becomes green and the other side become red then the ambulance can reach the hospital smoothly. The way to update the system dynamically by using SMS through the GSM module. The most important thing by using RFID is cost effective and then will provide uninterrupted communication even in bad weather conditions.

The works by Aswani [8] also uses RFID and GSM to prove that this devices can be used to control the traffic congestion. However, it has a bit different with Raju et al. [7] because it applied LPC2148 which is system-on-chip to read the RFID tags attached to the vehicle and the main goal of this research is to control the traffic light system for the emergency vehicle. He explained that this system can reduce the manual effort on part of traffic police to control traffic congestion and it also requires very less human intervention. Thus, it also can improvise his research by using Internet of Thing (IOT) to monitor the traffic signals density and control the traffic signals.

Chitta et al. [9] present a smart traffic light control system for emergency vehicles especially for ambulance to pass through traffic light junction smoothly by using RFID and IOT applications. The RFID reader will be installed at the traffic light junction meanwhile RFID tags fixed to the vehicles. Then, the total of the system can be monitored through IOT. As a result, his works might be saved the manual effort on the part of the police traffic to control the congestion by using IOT applications. Other than that, the integration between RFID and IOT application can create a new revolution to control the traffic congestion. Table 1 shows the summary for the RFID techniques based the references, proposed approach, advantages and disadvantages.

Table 1. Summary for RFID techniques

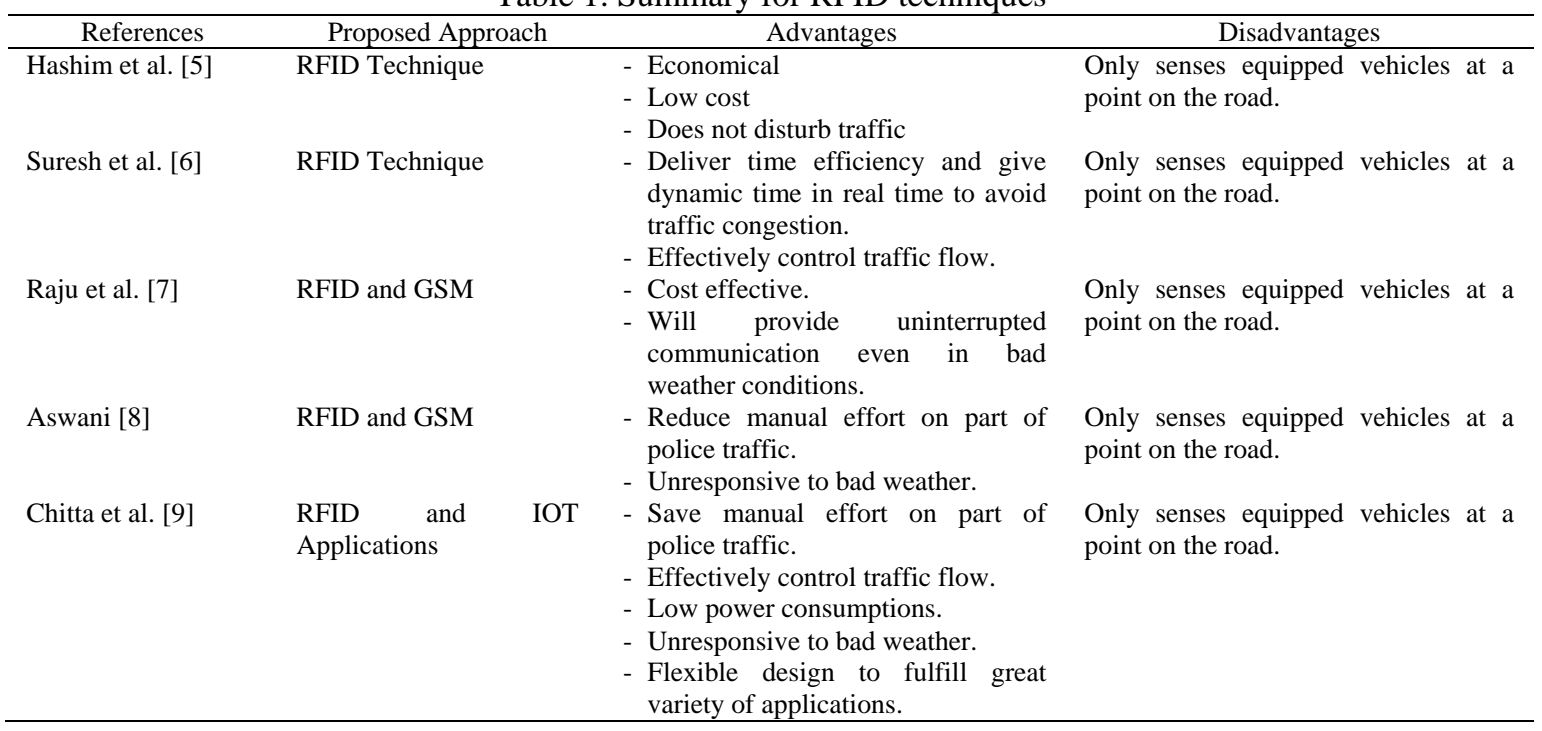

\subsection{Wireless Network Sensor (WSN)}

On the other hand, WSN can also be used to control traffic congestion on the road. There are several function of WSN that can be used such as to collect traffic data, actively controlling traffic and being placed on network controllers. Thus, WSN are very easy for installation, less of maintenance, faster transfer of information and less expensive compared to other network options. 
There are several important research on traffic light control for emergency vehicles using WSN techniques to prevent traffic congestion on the road [10]-[14]. For example, Shruthi et al. [10] propose WSN techniques to control both single and multiple intersection. This research is also designed to control traffic over multiple intersections and follows international standard for traffic light operations. The sensor will be installed on the traffic light and then the FR signals will be emitted by sensor located in the emergency vehicle. After being detected, the traffic light controller will change the light depend on its priority that is assigned to emergency vehicles. The weakness of this research is that it is necessary to process a large amount of real-time traffic data and time-consuming control systems need to be fast.

A study conducted by Nelloreet et al. [11] use WSN to provide a taxonomy of different traffic control system schemes that were used to avoid traffic congestion on the road especially for the emergency vehicles. However, [11] only focus on the traffic control system for priority based on signaling, reducing congestion and the average waiting time (AWT) of vehicles at intersection. The sensor network consists of two element which are the sensor nodes and the gateway nodes. The function of the sensor node is to monitor traffic congestion at certain area by measure several physical traffic such as density, volume and waiting time. The gateway note will collect all the traffic information from all the nodes and direct to the base station. As a result of the study, WSN can provide the mobility of sensors node, the ability to withstand harsh environmental conditions and low power consumption. The disadvantage of this research is using many nodes to produce more efficient coverage and coordination between nodes with central systems is a major problem.

However, unlike Yousef et al. [12] which explains that WSN can be used for an adaptive traffic light control system especially for single and multiple intersection. The purpose of using WSN is to route traffic based on traffic density and waiting time. The sensors are fitted on each road to detect the presence of vehicles and to store the waiting time in the memory. Then, all the data will process by the intelligent traffic controller based on two algorithms Traffic System Communication Algorithm (TSCA) which are Traffic Signal Time Manipulation Algorithm (TSTMA) to route the traffic variations of all lanes of intersections at a particular time and Traffic Control Algorithm on Multiple Intersections (TCAMI). TSTMA uses three techniques which are dynamic selection of traffic based on the number of lanes allowed in the junction, dynamic adaptation to the changes in the arrival and departure rates and lastly by using dynamic control of traffic cycle timing the traffic light periods. TCAMI uses to coordinate and settings of traffic parameters on the multiple junctions. The results of the study shown that this system had a better performance rate in managing traffic compared with the traditional traffic light control system. The disadvantage of this system is that it cannot adjust to the changing traffic situation. Then, for adaptive time control, the duration and sequence of all traffic phases are dynamic.

Goel et al. [13] further supports the study conducted by Yousef et al. [12] by developing a smart traffic lighting system to prioritize emergency vehicle based on WSN. This system works is where traffic lights from one intersection can communicate with the nearest intersection or next by using sensors and then giving priority to special vehicles by making traffic clearance. WSN can be used to get the information about the incoming flow of traffic, traffic load on a particular road and in vehicle prioritization. Then, WSN can be installed along a road to control the traffic load on the roads and at traffic intersections. Thus, the sensor nodes that are fitted along the road are have low energy consumption and small in size. The weaknesses of this technique is the routing problem which is the task of finding multi hop path from a sensor node to the base station.

Bhuvaneswari et al. [14] presents the traffic control system Adaptive Signal Traffic using the Wireless Sensors Network (ATSWSN). However, it is different from [12] based on the time slot allocated for each route not focusing on traffic density but also on emergency situations and speed patterns. This system uses an Infra-red (IR) sensor to collect real-time data and microcontroller algorithms to process data and then decide which direction to get green light preferences. The results of the study show that ATSWSN registers the higher traffic flow rate and produce the lower average waiting time. Sometimes, the sensor nodes are in sleep mode or switched off when not in operation is a weakness of this technique. Table 2 shows the summary for the WSN techniques based the references, proposed approach, advantages and disadvantages. 
Table 2. Summary for WSN Techniques

\begin{tabular}{|c|c|c|c|}
\hline References & Proposed Approach & Advantages & Disadvantages \\
\hline Shruthi et al. [10] & WSN Technique & $\begin{array}{l}\text { Control single and multiple } \\
\text { intersection. }\end{array}$ & $\begin{array}{l}\text { - Process a large amount of real- } \\
\text { time traffic data and time- } \\
\text { consuming control systems need } \\
\text { to be fast. }\end{array}$ \\
\hline Nelloreet et al. [11] & WSN Technique & $\begin{array}{l}\text { Provide the mobility of sensors node } \\
\text { and low power consumption. }\end{array}$ & $\begin{array}{l}\text { - Using many nodes to produce } \\
\text { more efficient coverage and } \\
\text { coordination between nodes with } \\
\text { central systems is a major } \\
\text { problem. }\end{array}$ \\
\hline Yousef et al. [12] & WSN Technique & $\begin{array}{l}\text { Control single and multiple } \\
\text { intersection. }\end{array}$ & $\begin{array}{l}\text { - Cannot adjust to the changing } \\
\text { traffic situation. }\end{array}$ \\
\hline Goel et al. [13] & WSN Technique & $\begin{array}{l}\text { Can be used to get the information } \\
\text { about the incoming flow of traffic } \\
\text { and traffic load on a particular road. }\end{array}$ & $\begin{array}{l}\text { - Routing problem which is the } \\
\text { task of finding multi hop path } \\
\text { from a sensor node to the base } \\
\text { station. }\end{array}$ \\
\hline $\begin{array}{l}\text { Bhuvaneswari et al. } \\
\text { [14] }\end{array}$ & WSN Technique & $\begin{array}{l}\text { Control single and multiple } \\
\text { intersection. }\end{array}$ & $\begin{array}{l}\text { - Sometimes, the sensor nodes are } \\
\text { in sleep mode or switched off } \\
\text { when not in operation }\end{array}$ \\
\hline
\end{tabular}

\subsection{Image Processing}

Another technique that can be used to control traffic congestions is to use an image processing approach. Basically, image processing is a technique to enhance a raw image that received from sensors or camera. Additionally, it is also reliable to estimate the presence of vehicles for using actual traffic images. So, image processing can be classified as a good technique for controlling the change of the state of the traffic light.

Chandrasekhar et al. [15] propose a system to control traffic congestion using digital image processing. The vehicle is detected by the system through the use of electronic sensors embedded in the pavement. The camera will be fitted with a traffic light to capture the image sequence. Then, the images captured in succession are matched using image matching with a reference image that is an empty road image. Traffic is controlled according to the corresponding percentage. For emergency vehicles, the analysis is calculated based on a flashing red light. The disadvantages of this technique are to perform more image processing processes to produce good image quality for the detection of emergency vehicles.

Jadhav et al. [16] demonstrated a smart traffic control system using image processing. The study was conducted using Matlab software and the main purpose was to prevent heavy traffic on the road. In addition, this study uses image processing techniques. The web camera is located in the traffic lane that will capture the street image. Then, these images are processed efficiently to determine traffic density. Based on data processed from Matlab, the controller will send instructions to LED traffic to indicate a specific time on the signal to manage traffic. This research is given to a certain roadway light according to traffic density on the road with priority given to the ambulance based on flashing red light. The disadvantage of this technique is to use image processing and Matlab software to process images that will cause much work to be done and cost increases.

Kaur et al. [17] also present a traffic management application using digital image processing. The methodology has been used are almost the same with [15],[16] by using camera. The camera is fitted on a long pillar from where the lane view can be taken very clearly. The function of the camera is to take images or videos of the lane to check out the traffic at any instant on the lane. The images that captured by camera will be processed using image processing techniques and the number of the vehicles on each lane is counted. However, the time is assigned to traffic light on each lane according to the count or the density of vehicle on that road with priority given to emergency vehicles. Emergency vehicles is detected by density of the flashing red light. As a result, by using multiple sequential cameras will help to increase the analysis of traffic congestion on the road. The disadvantage of this technique is to use a multiple of sequential cameras that will cause high prices and high maintenance.

Syawaludin et al. [18] made further support by using combination of HSV color space and RGB color space technique for intelligent traffic light system to detect emergency vehicles. The aims of this research is to develop a system that can control the traffic light for any emergency vehicles to pass through a road intersection smoothly and indirectly that will make the emergency vehicles reach the emergency site faster, hence many lives can be safe. This research also uses image processing techniques to detect emergency vehicles. The reason why using HSV color space and RGB color is to analyze the light of emergency vehicles and produce more accurate detection of emergency vehicles. The camera is fitted at the intersection and then the image will convert to frame by frame of images. The images processing techniques can be applied to detect the emergency vehicles from all the vehicles on the road from the frame of images. 
The difference of emergency vehicles with other vehicles is the emergency light on those vehicles. The disadvantage of this technique is to use a lot of cameras to process photos to get clear images and cause cost increases.

The study conducted by Gaikwad et al. [19] on image processing based traffic light control is aims to prevent heavy traffic congestion on the road. This study also use Matlab software to implement the system. It does not actually measure the number of vehicles that present on the road but it measures the area covered by vehicles on the road. Omkar Ramdas Gaikwad et al applied three steps to implement this study which are image acquisition, RGB to grayscale transformation and lastly image enhancement. The key point of the study is it used web camera which fitted in a traffic lane that will capture the image. Then, the images are efficiently processed to know the traffic density. The Matlab will process the data and the controller will send the command to the timer to show particular time on the signal to manage traffic. For the emergency vehicles, it also give priority based on flashing red light. The disadvantages of this technique are necessary to get a clear image from the best quality cameras before processing the image and produce good results. Table 3 shows the summary for the image processing techniques based the references, proposed approach, advantages and disadvantages.

Table 3. Summary for Image Processing Techniques

\begin{tabular}{|c|c|c|c|}
\hline References & Proposed Approach & Advantages & Disadvantages \\
\hline $\begin{array}{l}\text { Chandrasekhar et al. } \\
\text { [15] }\end{array}$ & Digital Image Processing & $\begin{array}{l}\text { Simple to add and change } \\
\text { detection areas. }\end{array}$ & $\begin{array}{l}\text { Perform more image processing } \\
\text { processes to produce good image } \\
\text { quality for the detection of } \\
\text { emergency vehicles. }\end{array}$ \\
\hline Jadhav et al. [16] & Digital Image Processing & Monitors multiple lanes. & $\begin{array}{l}\text { Process images that will caused } \\
\text { much work to be done and cost } \\
\text { increases. }\end{array}$ \\
\hline Kaur et al. [17] & Digital Image Processing & Offers broad area detection. & $\begin{array}{l}\text { Use a multiple of sequential } \\
\text { cameras that will cause high } \\
\text { prices and high maintenance. }\end{array}$ \\
\hline Syawaludin et al. [18] & $\begin{array}{l}\text { Digital Image Processing } \\
\text { (Combination of HSV color } \\
\text { space and RGB color space } \\
\text { technique) }\end{array}$ & $\begin{array}{l}\text { To analyze the light of emergency } \\
\text { vehicles and produce more } \\
\text { accurate detection of emergency } \\
\text { vehicles. }\end{array}$ & $\begin{array}{l}\text { Use a lot of cameras to process } \\
\text { photos to get clear images and } \\
\text { cost increases. }\end{array}$ \\
\hline Gaikwad et al. [19] & Digital Image Processing & $\begin{array}{l}\text { Simple to add and change } \\
\text { detection areas. }\end{array}$ & $\begin{array}{l}\text { Performance is sensitive to bad } \\
\text { weather, vehicles shadows and } \\
\text { dusts on the camera lens. }\end{array}$ \\
\hline
\end{tabular}

\section{PROPOSED METHOD}

Based on the reviewed literatures, it can be concluded that RFID technique is the best technique to implement a smart traffic light control system especially for emergency vehicles because of low maintenance, low price and can be used in various areas of applications. Based on RFID's literature reviews indicate positive results when applied it on the system.

In Malaysia, where the economic situation is in the stage of development and control of the existing traffic light is not enough to control the increasing of vehicle. Therefore, this proposed method takes all consideration based on the problems that occur to improve the existing traffic light control system for emergency vehicles.

The main purpose of this paper is to provide clear paths to emergency vehicles and then traffic signals should switch automatically to give way to the emergency vehicles. In the proposed method, the design for this system is divided in three systems. Firstly, is fitted in an emergency vehicle and known as an Emergency Vehicles System (EVS). Secondly, is fitted at traffic light junction and known as Traffic Junction System (TJS). Lastly, known as Base Station System (BSS). These three systems need to communicate to each other. The further details to explain about these three systems as below:

\subsection{Emergency Vehicles System (EVS)}

The elements that should have for the emergency vehicles system is RFID tag, GPS, microcontroller, Zigbee, power supply, GSM and LCD display. This element play an important role to EVS. The function of RFID tag is to store all the information about vehicles such as vehicle's registration number and type of vehicles. The GPS will be given an information the location of the emergency vehicles. The microcontroller calculates the direction of the emergency vehicles by using GPS and then send the signal to traffic junction system to change the signal from red to green. The microcontroller is plays major role. It is 
used as a component in complicated process control system. The function of LCD is used to display the information about the current process. To illustrate this, consider Figure 1 shows the component for EVS.

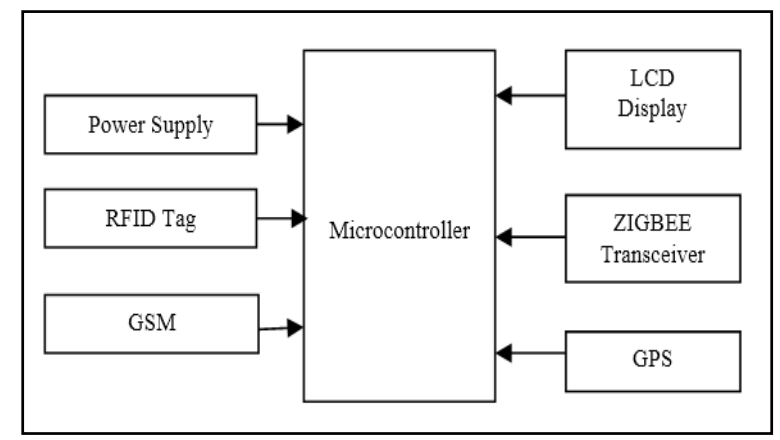

Figure 1. Component for EVS

\subsection{Traffic Junction System (TJS)}

The main elements for the traffic junction system is RFID reader, microcontroller, power supply and Zigbee. The function of RFID reader is to read the information from RFID tag and the RFID reader is installed at the traffic light junction. The function of power supply is to provide the current to the system. Zigbee is a wireless technology that was guided by IEEE 802.15.4 personal area network standard (WPAN). It is used to wide ranging controlling and replace the existing non-standard technologies. Once the RFID reader receive the data and then send in to the microcontroller. The microcontroller process the data and give the instruction that the lane on which emergency vehicles is coming, then turn the green color on that lane. To illustrate this, consider Figure 2 shows the component for TJS.

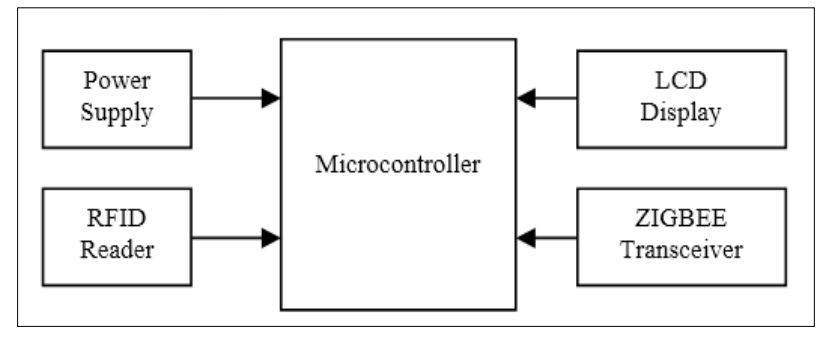

Figure 2. Component for TJS

\subsection{Base Station System (BSS)}

The function of BSS is to control and store all information about vehicle's movement. The GSM will be used for receive and send messages. To illustrate this, consider Figure 3 shows the component for BSS.

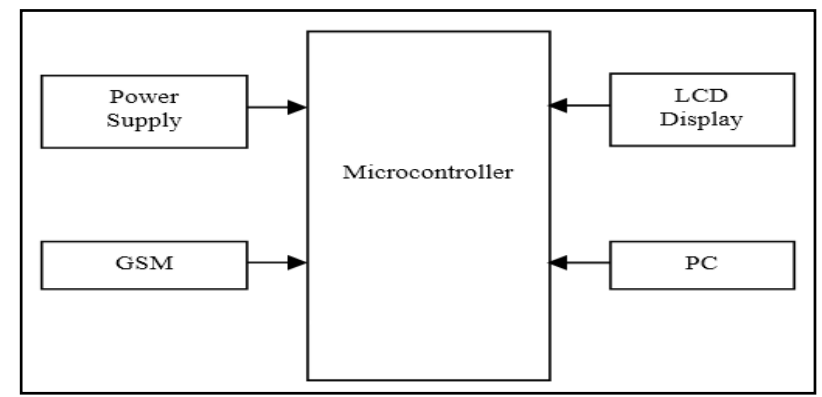

Figure 3. Component for BSS 


\section{DISCUSSION}

The research problem is there are traffic congestion occurred everyday on the roads. So, the people have to wait for a long time on the traffic congestion. It may cause difficulty for emergency vehicles to pass through the intersection with traffic light. Some interruptions are possible over with the road users. It is because the road users need to compromise with this situation to protect someone's life.

The ideal way to propose the best technique is to review the literature on the relevant techniques used to control traffic lights especially for emergency vehicles. For each technique, five previous studies have been reviewed. Then, the comparisons were made based on the results of each study, the advantages and the disadvantages of each technique.

RFID is the best technique compared to other techniques because of low price, low maintenance and can be used in various areas of applications such as military, medical science, commerce, electronic toll collection systems and so on. For example, RFID technique can be considered as a low price for communication because it can provide uninterrupted communication to the network even in bad weather compared to unstable WSN during bad weather [20].

A study conducted by Chitta et al. [9] have proposed RFID technique as the best technique to solve traffic light problems for emergency vehicles. This is because the integration between RFID and GSM and Internet technologies can produce a great revolution for smart traffic control systems. The system can also store data that can be used by operators and planners to improve the system in the future. Additionally, systems developed by Chitta et al. [9] provide good results while reducing costs and minimizing maintenance.

\section{CONCLUSION}

As a conclusion, the implementation of smart technology in the transportation system can produce a great impact on traffic levels especially for the emergency vehicles. This paper reviews the literature on the relevant techniques used to control traffic lights to provide a clear path to the emergency vehicles and will make the emergency vehicles reach the emergency site faster. This paper also compares the techniques used to control traffic light such as RFID, image processing and WSN.

The finding of this paper indicates that RFID is the best technique to control the traffic light for emergency vehicles. As a future work, the RFID technique also can be used on VVIP vehicles and military convoys to avoid getting stuck in the traffic congestion. Other than that, it can give researchers the idea of developing a smart system to control road traffic in the future.

\section{ACKNOWLEDGEMENT}

The authors would like to thank the Universiti Teknologi Mara for their financial support to this project under BESTARI Grant No. 600-IRMI/PERDANA 5/3 BESTARI (105/2018).

\section{REFERENCES}

[1] Malaysia Automative Association, "Summary of Sales \& Production Data MAA Newsletter August 2017," Kuala Lumpur, 2017.

[2] K. Sangeetha, et al., "Automatic Ambulance Rescue with Intelligent Traffic Light System," IOSR Journal of Engineering, vol/issue: 4(2), pp. 53-57, 2014.

[3] http://www-05.ibm.com/za/office/pdf/IBM - A Vision for a Smarter City - Nairobi.pdf.

[4] http://www.impinj.com/resources/about-rfid - howdorfidsystemswork.

[5] K. Athavan, et al., "Automatic Ambulance Rescue System," 2012 Second International Conference on Advanced Computing \& Communication Technologies, 2012.

[6] S. Sharma, et al., "Traffic Light Priority Control for Emergency Vehicle Using RFID," International Journal of Innovation in Engineering and Technology (IJIET), vol/issue: 2(2), 2013.

[7] T. N. Raju, et al., "Smart Traffic Light Control System for Emergency and Detection of Stolen Vehicles," International Journal of Advanced Research in Science, Engineering and Technology, vol/issue: 1(5), 2014.

[8] D. Aswani, "Smart Traffic Control System for Emergency Vehicle Clearance," International Journal \& Magazine of Engineering, Technology, Management and Research, vol. 3, 2016.

[9] A. S. Chitta and Dinesha P., "Priority Management of Emergency Vehicles Using IOT Approach," International Journal of Advanced Research in Computer and Communication Engineering, vol/issue: 5(9), 2016.

[10] Shruthi K. R. and Vinodha K., "Priority Based Traffic Lights Controller Using Wireless Sensor Networks," International Journal of Electronics Signals and Systems (IJESS), vol/issue: 1(4), 2012.

[11] K. Nellore and G. P. Hancke, "A Survey on Urban Traffic Management System Using Wireless Sensor Networks," 2016. 
[12] K. M. Yousef, et al., "Intelligent Traffic Light Flow Control System Using Wireless Sensor Networks (WSN)," Journal of Information Science and Enginering, vol. 26, pp. 753-768, 2010.

[13] A. Goel, et al., "Intelligent Traffic Light System to Prioritized Emergency Purpose Vehicles based on Wireless Sensor Network," International Journal of Computer Applications, vol/issue: 40(12), 2012.

[14] P. T. V. Bhuvaneswari, et al., "Adaptive Traffic Signal Flow Control usingWireless Sensor Networks,” pp. 85-89, 2012.

[15] Chandrasekhar M., et al., "Traffic Control Using Digital Image Processing," vol/issue: 2(5), 2013.

[16] P. Jadhav, et al., "Smart Traffic Control System Using Image Processing," International Research Journal of Engineering and Technology (IRJET), vol/issue: 03(03), 2016.

[17] G. Kaur and S. Sharma, "Traffic Management Using Digital Image Processing," International Journal of Computer Science and Technology, IJCST, vol/issue: 8(2), 2017.

[18] M. Syawaludin and M. R. Daud, "Detection of emergency vehicles using combination of HSV color space and RGB color space technique for intelligent traffic light system," 2015.

[19] O. R. Gaikwad, et al., "Image Processing Based Traffic Light Control," International Journal of Science, Engineering and Technology Research (IJSETR), vol/issue: 3(4), 2014.

[20] S. Djahel, et al., "Adaptive Traffic Management for Secure and Efficient Emergency Services in Smart Cities," IEEE, 2013. 